\title{
Boho-Chic Style Utilizing for Fashionable Apparel Design
}

\author{
Rehab Mahmoud Kotb \\ Lecturer of Textile \& Clothing, Faculty of Women for Arts, Science, and Education, Ain Shams University, Cairo, Egypt
}

Email address:

rehabmkotb@yahoo.com

To cite this article:

Rehab Mahmoud Kotb. Boho-Chic Style Utilizing for Fashionable Apparel Design. American Journal of Life Sciences. Vol. 3, No. 3, 2015, pp. 223-229. doi: 10.11648/j.ajls.20150303.24

\begin{abstract}
The convergence of art and fashion had already been fully developed many years ago. Today, they have combined together in a productive relationship that stimulates the creative expression of a new lifestyle. The term "Bohemian" has often been used to refer to the fashion and lifestyles of writers, artists, and other individuals who live outside of the norms and standards of other members of society. Bohemian fashion more recently developed to the term "Boho-Chic" that is largely inspired by the bohemian styles of the nineteenth century with some influences of recent fashion trends. It is a very appealing style that has found its way into a number of different fashions for women. The features of Boho-Chic are notable in that they can create some details that are very specific and unique around the build of an outfit or other kind of fashion. This style is one of the most interesting fashion styles of today which requires a great fashion sense to be able to put the right pieces together to create an enviable and unique look. In this research the fashion elements of this revival style are utilized in contemporary apparel designs, which reflect the aesthetic features of the Boho-Chic to connect the human with world and nature.
\end{abstract}

Keywords: Boho, Fashion Design, Apparel, Inspiration

\section{Introduction}

Fashion fulfills its fundamental function when worn by human, whether that function is to protect the body or to create a symbolic meaning. In addition, the action of choosing clothes, wearing them and making a style is a kind of art, where all individuals are a living form of artwork.

Inspiration can be derived from any concept, but art has a special connection to fashion. Just as fashion is an expression of ideas and emotions, so is art. It is imagined that there are reciprocal forces between the two concepts, art influences fashion and fashion influences art and some contend that fashion is art. Regardless of this ongoing debate, fashion designers should become apprised of modern art movements and remain curious concerning events in the contemporary world of art. This activity looks at the connections between art and fashion. Throughout history artists used many different styles to represent concepts, and fashion can relate to them all. [1]

\section{Origin of the Bohemians}

The Bohemians, as a counterculture, appeared in France after the French Revolution. Deprived of the former system of patronage, where wealthy clients supported the arts, artists were plunged into poverty. Many took up a nomadic life style, lived cheaply, and wore worn out and unfashionable or used clothing.

Formerly, an artist was seen as a skilled and talented crafts person. But the Romantic Movement of the late 18th century rejected the confines of bourgeois life and the former importance placed on reason, to embrace the imagination. A new cult of personality emerged with the artist as hero and individual style expressed in the way one dressed. An artist became a special type of person, not merely a crafts person, but a kind of eccentric genius whose creativity was displayed in the way they lived and looked. [2] People compared the new artistic types to wandering Gypsies and believed that Gypsies originated in Bohemia, an area of Eastern Europe and the Balkans. So, they came to refer to artists and intellectuals as Bohemians. Gypsy was a European term for the Romany people, an ethnic group with Indian origins who had migrated north. The word Gypsy, derived from the word Egyptian, which many thought the actual home of the nomadic people who were often social outcasts that lived outside the mainstream. $[3,4]$

\section{Bohemian Fashion History}

In earlier times dress had signified social status, a trade, 
membership of a princely retinue, or a profession. Now, dress became part of the performance of an individual personality, as the young Bohemians used costume to signify their poverty and originality. There was no single chronological line of development in Bohemian dress; rather, there were several different strategies: [2]

\subsection{The 1830's Bohemian Establishment}

By the 1830's, the French Bohemian art crowd and the Romantics embraced medieval and oriental clothing styles. With their colorful fabrics, long flowing hair, and wide brimmed hats, the artistic culture did come to resemble Gypsies.

A second style, described by the novelist Henri Murger wrote tales about the people that he called Bohemians, centering on a group of artists and intellectuals in threadbare coats, and old shoes. The stories inspired Puccinni's famous opera, La Boheme.

A third influential style was that Bohemian style evolved into a cult of the individual, a person whose very appearance became a work of art with carefully planned outfits and accessories. The word Bohemian suggested a sense of arcane and enlightenment. Bohemian life rejects materialism, private property, and centers on creativity and communal living. Often Bohemians ignore social convention and centering their lives on art. [5]

\subsection{Bohemians in the 19th Century-the Aesthetic Movement}

In the 19th century, the Aesthetic Movement became a type of Bohemian life style. The Aesthetics rebelled against the rigid social constraints of the Victorian era and embraced a style based on the clothing of the past, particularly medieval dress and oriental designs. Believing that the mass production of the Industrial Revolution was dehumanizing, the Aesthetics strove to encourage the old techniques of the middle ages with individually crafted goods. Clothing was loose and soft, using fabrics colored with organic dyes and decorated with hand embroidery. The Pre-Raphaelite artists rejected corsets, crinolines, and the stiff bodices and restrictive clothing of Victorian fashion. [6]

\subsection{The 20th Century Hippie Bohemian Style}

The early 20th century fashion designer reworked a variety of ethnic designs for Western fashion. The clothes originated from combination styles and elements of Russian peasant costume, Middle Eastern, Oriental, Africa, Caribbean, South Asia and historic dress which introduced Bohemian concepts in high fashion that eventually bled into mainstream fashion.

The Hippie Movement of the late 1960's incorporated Bohemian ideals. Centered on creativity of life and dress, Hippie style included elements of historic costume, ethnic dress, the casual neckties, romantic robes inspired black uniform, using the natural fibers, and a rejection of mainstream life. [6]

\subsection{Modern Bohemian or Boho-Chic Style}

Fashion designers in recent days introduce Bohemian style garments, so nature of the Bohemian life has become a cultural norm, and no longer unique and specific to a particular group. Yet what was once the casual originality of Bohemian dress has become the height of celebrity fashion and of high-street style. It therefore follows that in the twenty-first century, when everyone is Bohemian, no one can any longer be. [2,7]

Years 2004-2005 have imposed fashionable Bohemian style which referred to "Boho-Chic" fashion. 'Boho' is an abbreviation of Bohemian and 'Chic' means stylish or elegant. Boho-Chic is a female style of fashion pulling on various Bohemian and Hippie styles, which is all about expressing identity with a free sense of mind; and inject personality into the style. It's not just a fashion, it's a personality. The key to Boho-Chic is to look the opposite of tidy or precise. $[8,9,10]$

Boho-Chic fashion includes several different distinctive styles that range from artistic to exquisite.

A) Peasant Girl Boho-Chic:

Peasant-girl Boho-Chic style is very feminine and dainty. It includes long, flowing skirts made of lightweight natural materials in soft colors. Headbands, hair clips adorned with flowers, clothing items made with lace and embroidery, peasant-style tops and floral patterns are all common. Long, messy, but neat hair is typical for those who adapt the peasant-women Boho-Chic style; as shown in figure (1).

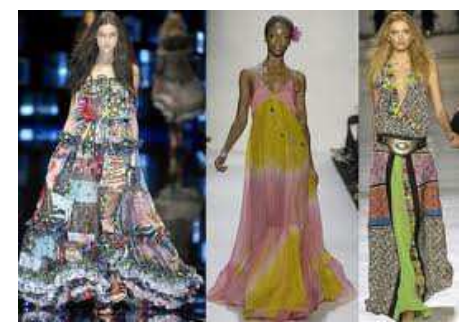

Figure (1). Examples for Peasant Boho-Chic style.

B) Rugged Boho-Chic:

Rugged Boho-Chic style is a little more unpolished and unrefined. Well-worn and tattered denim shorts, pants or skirts are typical basis for dress in this style. Brightly colored tunic tops and feminine cowboy boots are often worn with denim. Accessories include colored scarves and shiny bangle bracelets; shown in figure (2).

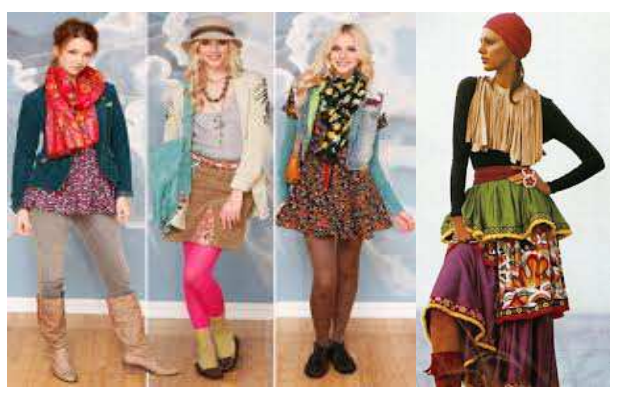

Figure (2). Examples for Rugged Boho-Chic style. 
C) Luxe Boh-Chic:

For the higher-maintenance Boho-Chic women, Bohemian luxe style incorporates all of the elements of Bohemian and throws in modern and classic elements of designer, in addition to use heels and sparkly jewelry. It has an overall polished look while still maintaining uniqueness and creativity. Long but modern flowing dresses, such as maxi dresses, are a favorite style among women who adapt the Bohemian Luxe style; shown in figure (3).

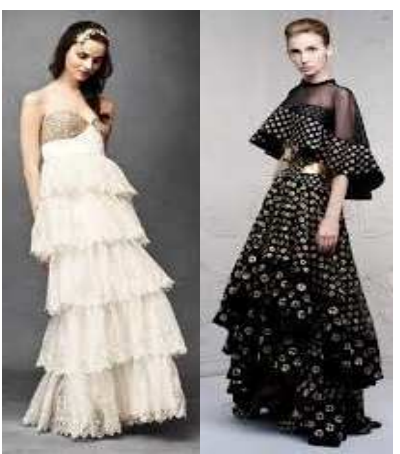

Figure (3). Examples for Luxe Boho-Chic style.

D) Hippie Boho-Chic

Hippie Boho-Chic style borrows fashion trends from the 1970s for an artistic and unconventional look. Fringe, floppy hats, brightly colored skirts and wide-legged cotton pants are all commonly seen in this style. Vintage items are popular among this crowd of Boho-Chic style enthusiasts; shown in figure (4). [11]

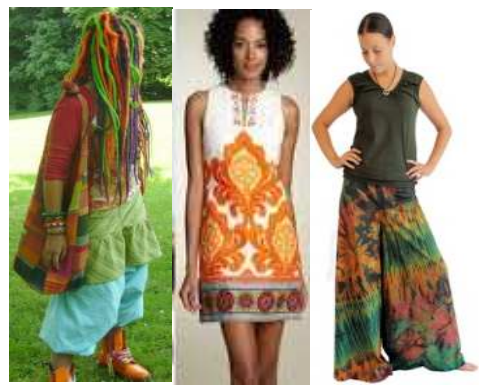

Figure (4). Examples for Hippie Boho-Chic style.

\section{Fashion Elements of Boho-Chic Style}

The clothes worn by women have colorful skirts with more long layers; more accessories are worn like bracelets, necklaces and scarves. For 200 years, Bohemian style has consisted of several fashion elements; which shown in figures (5), (6), (7), (8), and (9); are: [6,7]

- Freedom of motion is a major element of the BohoChic style. Rather than tight pieces.

- Flowing clothing made of natural fabrics.

- Less restrictive garments worn without corsets, bras or other restrictive elements.

- Loose and flowing hair.

- Colorful scarves worn at the neck, on the head, or instead of a belt.
- Peasant style clothing including tunics, loose trousers, boots, and sandals.

- Used or worn clothing.

- Oriental elements including robes, kimonos, and the ethnic designs of Persia, India, Turkey, and China.

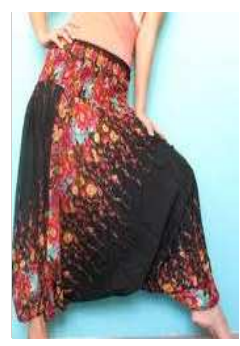

Figure (5). Ethnic and flowing clothes.

- Mixing historical elements of medieval clothing with modern styles.

- Layering.

- Multi strands of beads, several bangle bracelets, and the wearing of unusual, hand crafted, or unmatched jewelry. Large dangle or large hoop earrings.

- Patched clothing.

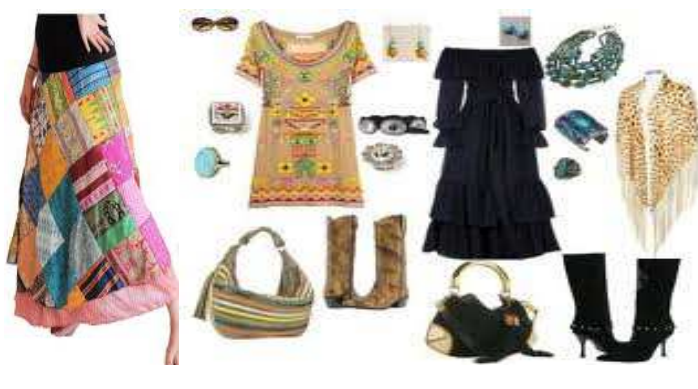

Figure (6). Patched clothes and accessories.

- Paisley, flowered fabrics, ruffles, lace edged sleeves.

- A general disregard for tidiness and uniformity of dress.

- Dressers opt for baggy and comfortable clothing.

- Maxi dresses; caftans; and Hippie or Gypsy skirts.

- Pieces are usually flared and available in a variety of colors and patterns.

- Matching of garments in a nontraditional manner, such as mixing prints, or unusual color combinations.

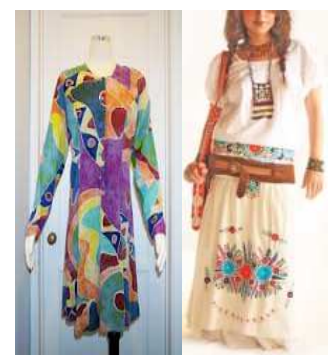

Figure (7). Unusual fabric prints and maxi style dress.

- Mismatched items are often paired with colors or patterns that wouldn't traditionally be worn together.

- Certain styles of pants such as gaucho pants or harem pants are popular for their flared, baggy style which 
allow for lots of space and movement.

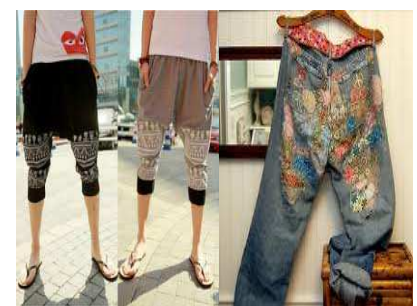

Figure (8). Different pants styles.

- Scarves, vests, jackets, and skirts are often worn on top of each other.

- Broad brimmed hats.

- Leggings are paired with a peasant blouse for a more modern look. Romantic touches, like flower patterns and lace. $[6,8,12,13]$

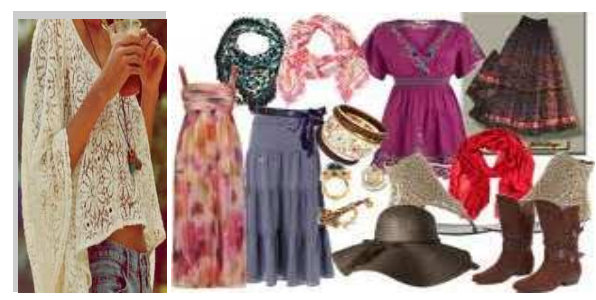

Figure (9). Lace and Peasant clothes.

\section{Simple Steps to Have the Boho-Chic Style}

There are few simple steps for any woman to obtain BohoChic style.

Step1. Study fashion-forward icons. They don't necessarily have to be Boho-Chic embracers, but more than likely. Devour fashion magazines, and try to find what makes a woman to be fashionable apart from other people and start to develop the own way for looking at fashion.

Step2. Do as most adorn. Boho-Chic doesn't just mean flown peasant skirts, flip flops, and messenger bags. An important aspect of this style is individuality; this means embracing own personality and expressing it through fashion choices. Boho-Chic style may be described as a trend with certain looks to follow, but it is really all about following own inspirations.

Step3. Mix it up. Learn how to pair pieces in the wardrobe together, when using imagination, much more life can be added. For example; pairing a frilly white shift dress with a brown shawl and olive flats, or mixing a red trench coat, black tights, and a vintage turquoise belt. The possibilities are truly endless.

Step4. Accessorize. In the world of Boho-Chic, extreme attention is paid to details. From long and layered necklaces, bracelets and head scarves, belts, moccasins, cowboy boots, leggings, ballerina flats, platform shoes, and sequined vests, it is all about the small things.

For example, an ordinary woman might take a white oxford blouse and pair it with a black pencil skirt, black patent pumps, or a red leather handbag. But, a woman with a Boho-Chic attitude would arrive at the same classic/modern look by wearing the same blouse underneath a black 1920s style shift dress, adding black tights and ankle boots, and a hair accessory such as a red knit beret or a clustered clip of gemstones. Boho-Chic style represents a state of mind, which regarding fashion is an individual, romantic, and free-spirited sense for clothes items mix and match.

\section{Apparel Designs Inspired by Boho- Chic Style}

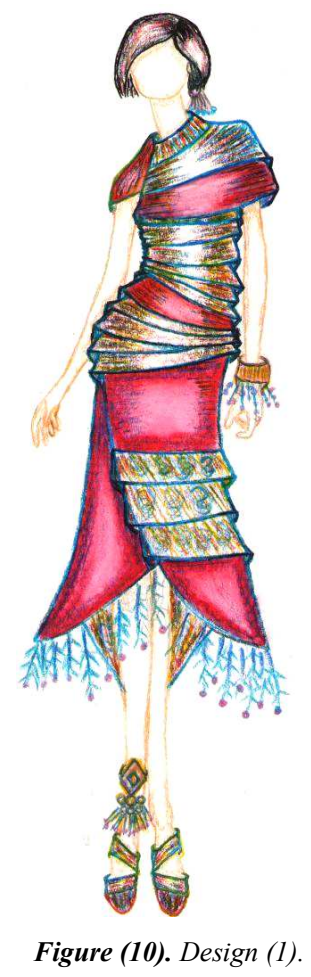

Design (1):

The design shown in figure (10) is a combination of Hippie and Luxe Boho-Chic types which gain the classic fashion elements such as drapes in a novel mix with the sarong skirt from modern fashion trends.

The Boho-Chic fashion elements are clearly obvious from using the mock turtle neckline of 1970s Hippie nourishing mixed with raglan sleeve giving modern, individual and youthful spirit to the design. The consequent drapes in several sizes and directions are manipulated in different ways. The sarong skirt in short length inspired by Luxe type has a bright and feminine color combination. Besides using the horizontal gradated patched fabrics which are important key in Boho-Chic style. Wearing the large dangle bracelet decorated with stones and beads, in addition to the unconventional anklet made from metal are matched with modern sandals, support the Hippie/Luxe elements in all design details. The design has elegant and polished look while still maintaining uniqueness and creativity spirit. 


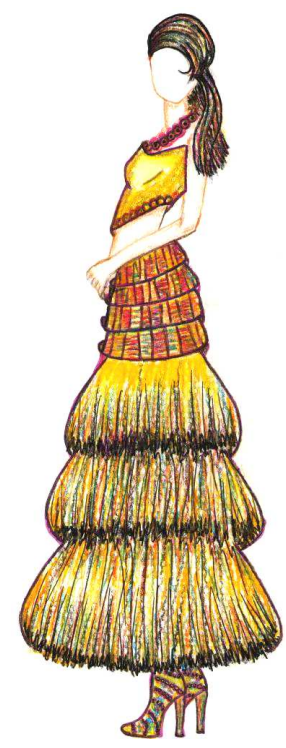

Figure (11). Design (2)

\section{Design (2):}

This design is classified as Luxe Boho-Chic type; as shown in figure (11); because it has more details; it is a long but modern flowing two pieces dress. It consists of upper boat shape bodice and layered loose skirt, in-between there are horizontal large pleats that are parallel and sequent to each other. The lower skirt has multilayer, which consists of three flounced gathered cuts create gradation in size and length.

The Boho-Chic elements appear in all over the design details such as; delicate and detailed hand craft circles rising from bodice upward around the neck in a shape of necklace; the modern printing pattern in the horizontal pleats; the gathered flowing skirt; using boots with fine decoration. Also the colors are mixed in a shiny and glamour combination that indicates the design nature.

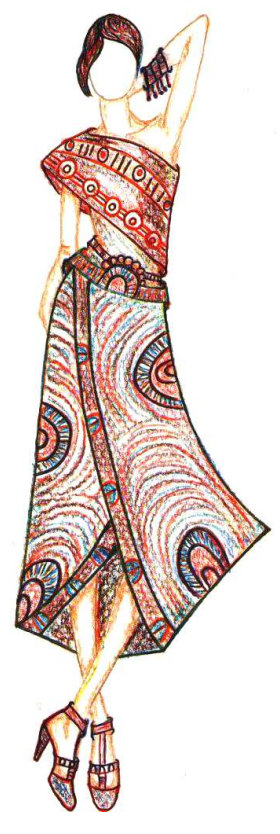

Figure (12). Design (3).
Design (3):

The design shown in figure (12) belongs to Hippie BohoChic category which borrows fashion trends from 1970s for its artistic and unconventional look. It consists of wrapped diagonal long shawl with flowing wrapped skirt.

The Boho-Chic elements are represented in the brightly colored unusual mix; the vintage look; mixing the historical shawl style of Rome with modern skirt lines; beads work in shawl; metal belt around the waist. In addition to the print pattern of the skirt which inspired by modern art features; the multi strand bracelet that made from modern metals and beaded fringe. Sandals also are beaded creating a sense of harmony; colors are mixed in random and emphasized mix which indicate the whole spirit individuality and spirit.

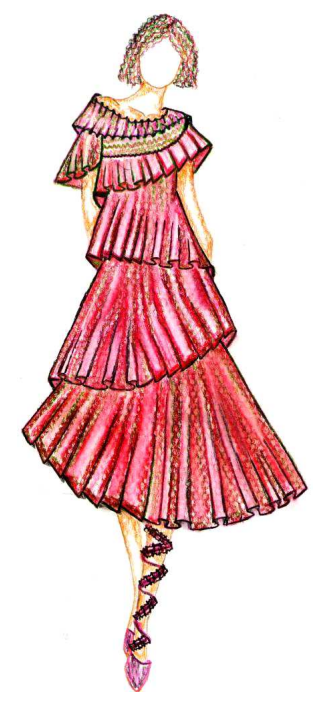

Figure (13). Design (4)

Design (4):

It is a Peasant Boho-Chic style, which is very feminine and dainty, as shown in figure (13). It is midi length flowing and loose dress, it is considered a less restrictive garment worn without restrictive elements. It is made of multilayered flowing diagonal pieces in soft colors with different hues and tones.

The Boho-Chic elements are present in using layered fabrics and pieces that are over each other, also by using pleats and flounced cuts which are in gradation. The sense of freedom and individuality of Boho-Chic woman is indicated throughout the loose style of the whole dress. Sandals also have ruffled strands made of crochet hand work, which support historical/modern style combination and rising upward around the leg to the knee. The short curly messy hair but neat is a typical feature of Boho-Chic look.

Design (5):

The design shown in figure (14) is a combination of Rugged and Hippie Boho-Chic category. It has a little more unrefined details and well-worn look. The design consists of three pieces; the bodice covering one shoulder, the layered short float skirt; and legging. The skirt pieces are flared in different techniques such as horizontal large drapes, vertical gradated pleats and diagonal flounced hemline. The design 
has more sophisticated details providing the unconventional and informal look.

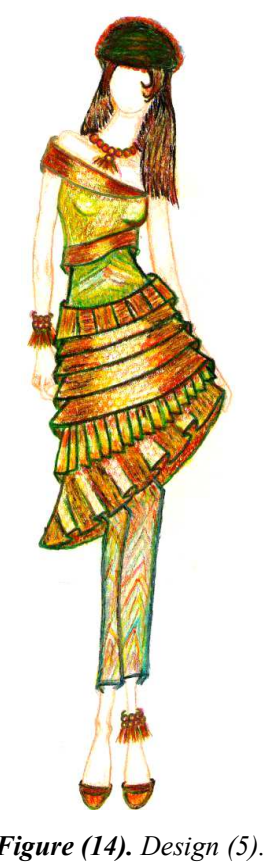

The elements of Boho-Chic in this design rise from using multilayered skirt mixed with asymmetrical two bodices, which are worn on top of each other adding a romantic touch to the design. Also, using leggings which are one of the important elements in this style type give a modern look. The combination of shiny hot colors gives the design unusual appearance. The feminine brimmed hat, in addition to the beaded accessories such as hand crafted stone necklace, bangle bracelet, and multi beads strand anklet support the overall style. The design as a whole creates relaxed fashionable and aesthetic look.

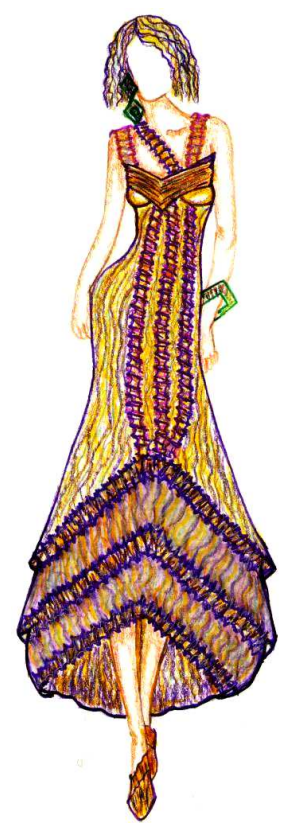

Figure (15). Design (6).
Design (6):

This style; as shown in figure (15); is a typical example of Luxe Boho-Chic type which is characterized by incorporating historical elements such as ruffles; which create the main theme of the design into modern details. The feminine fishtail silhouette and the loose flowing multilayered in the lower part give a natural look to the design.

The Boho-Chic elements are obvious in using multi shoulder stripes by ruffles technique, the thin and elegant drapes in the bra cut, and the diagonal different ruffles lengthwise the dress. The flared and puffed layers in the lower part which are over each other create gradation in size and flounce. The messy and modern hair cut, the large dangle hoop earning, and the hand work shiny bracelet complete the design style. In addition, the classic/modern sandals and the unusual color combination give a sparkly elegant look.

\section{Conclusion}

Fashion is about change and about challenging what have gone before; it is about leading, not following, and pushing design visions into the world. This research is an in-depth trial for starting journey of discovery and exploring in BohoChic style history and development. Boho-Chic style is a combination of many fashion clothing and accessories from vintage styles and the modern era. It combines organic, colorful, detailed, folk-inspired pieces with simple, modern ones.

In this research, a suggestion of few simple steps for building a Boho-Chic wardrobe is proposed. In addition, from the unique characteristics of this innovative style, six fashionable feminine apparel designs have been created throughout giving an insight the Boho-Chic style, which reflects the convergence of art and fashion in our life stream.

\section{References}

[1] T. Jennings, Creativity in Fashion Design, Fairchild Books, Condé Nast Publications, USA, 2011.

[2] V. Steel, Encyclopedia of Clothing and Fashion, Volume 1: Academic Dress to Eyeglasses, Thomson Gale, Thomson Corporation, USA, 2005.

[3] S. Pendergast and T. Pendergast, Fashion, Costume, and Culture: Clothing, Headwear, Body Decorations, and Footwear through the Ages, The Gale Group Inc., Thomson Learning Inc., USA, 2004.

[4] D. R. Eikhof and A. Haunschild, Lifestyle Meets Market: Bohemian Entrepreneurs in Creative Industries, Journal: Creativity and Innovation Management, 15, (3), 2006, 234241.

[5] V. Steel, Encyclopedia of Clothing and fashion, Volume 3: Occult Dress to Zoran Index, Thomson Gale, Thomson Corporation, USA, 2005.

[6] D. Monet, Boho-The Fashion history of Bohemian Style, http://www.doloresmonet.hubpages.com, (January, 2013). 
[7] A. F. Avrigeanu and F. G. Anghel, Romanian Clothing Industry: External Market VS. International Market, Journal: Romanian Economics and Business Review, 6, (1), 2011, 6776.

[8] R. Kittler, Everything You Need to Know About Boho-Chic, http://www.isnare.com, (March, 2010).

[9] A. Adams, All About The Boho-Chic Style, Business Articles, August, 2013, 1-3.
[10] K. L. Kenney, Boho Fashion, Lerner Publications, USA, 2014.

[11] J. Aguillard. What Is Boho-Chic, http://www.ehow.com/BohoChic.html, (February, 2013).

[12] S.Schmidt, What Is Bohemian Fashion, Conjecture Corporation, USA, 2003.

[13] J. Adams, What Is Boho-Chic,

http://www.wisegeek.com/what-is-boho-chic.htm, (May, 